\title{
Influence rocks mass and explosives properties on dissipative energy losses during blasting
}

\author{
Valentyna Nykyforova ${ }^{1}$, Ernest Yefremov $^{1}$, Ihor Kratkovskyi ${ }^{1, *}$, and Volodymyr Kurinnyi ${ }^{2}$ \\ ${ }^{1}$ Institute of Geotechnical Mechanics named by N. Poljakov of National Academy of Sciences of \\ Ukraine, 49005, Dnipro, Simferopolska Str., 2a, Ukraine \\ ${ }^{2}$ National University Dnipro Polytechnic, 49005, Dnipro, Yavornytskoho Ave., 19, Ukraine
}

\begin{abstract}
The factors affecting the energy explosion loss on rock crushing on con-tact with explosives have been established. This makes it possible to substantiate ways to increase low explosion efficiency. Theoretical estimates of the explosion energy losses during the rocks destruction have been carried out taking into account the explosives properties and heterogeneities in the rocks structure. It has been established that homogeneities in the form of mineral grains of various strengths determine the mechanism of their destruction and crushing during blusting. A thermodynamic loss has been estimated during the expansion of gaseous detonation products, on which the maximum explosion work depends. These losses characterize the theoretical possibility of the transfer of energy stored in an explosive into mechanical work. The explosion losses associated with the origination of shock waves in rocks are also have been determined.
\end{abstract}

\section{Introduction}

At present, works on the mechanism of rock destruction in the explosion near zone are of great interest, since more than $90 \%$ of the energy contained in explosive is expend on blasting (rock crushing) on contact with it [1-5]. Industrial blasting use ultimately has a constructive character, despite the fact that this process is associated with the destruction of the medium subjected to explosion effect.

The source of the explosion work is the potential energy of explosives released during its detonation. However, not all the potential energy of explosives goes into work, some of it is lost. These can be chemical losses resulting from the dispersion of unreacted explosive particles and the incompleteness of its detonation. Apart chemical losses, there are also thermodynamic losses, the magnitude of which depends on the composition and properties of detonation products [6].

The maximum work that the explosion products can do is work on its adiabatic expansion (without sharing with the environment). This work is a measure of the ideal explosives performance, one of its important energy characteristics. It complements the explosion work, indicating the theoretical possibility of the transfer of energy stored in

\footnotetext{
*Corresponding author: kratkovsky@i.ua
} 
explosive into mechanical work, and is determined not only by the explosion heat, but also depends on the chemical composition and certain physical properties of the explosives.

The ideal work of explosives $A_{i}$ can be defined as the difference between the internal energy of the explosion products at the time of their formation with the temperature $T_{1}$ and at the end of their expansion to atmospheric pressure $\left(P_{0}=0.1 \mathrm{MPa}\right)$ and temperature $T_{2}$ :

$$
A_{i}=\bar{C}_{v 1} T_{1}-\bar{C}_{v 2} T_{2}
$$

where $\bar{C}_{v 1}$ and $\bar{C}_{v 2}$ - the average values of heat capacities with a constant volume in the temperature range $T_{1}-T_{2}$.

The term $\bar{C}_{v 2} T_{2}$ is the lost heat, which remains in the explosion products when they reach atmospheric pressure, which cannot go into work.

Thus, the heat loss depends on the heat capacity of the explosion products. With equal heat of explosion, heat losses increase with the presence in the explosion products of solids having a high heat capacity. With an increase in heat losses, the work of the explosion decreases, therefore, the efficiency of the explosion $\eta$ decreases.

For an ideal adiabatic process, the efficiency of an explosion is determined by the expression:

$$
\eta=\frac{A}{Q}=1-\left(\frac{P_{2}}{P_{i}}\right)^{\frac{k-1}{k}},
$$

where $P_{i}$ and $P_{2}$ - are, respectively, the explosion products initial pressure on the charging cavity surface and the pressure at the time point when it expanded, doing work $A$; $Q$ - the explosion heat; $k$ is the adiabatic index.

The numerical value of $k$ is determined by the properties of the explosion products. It is more in cases when diatomic molecules prevail in the explosion products, and decreases with an increase in the fraction of triatomic molecules. The value of $k$ is especially reduced when there is a condensed phase in the explosion products.

With decreasing $k$, the efficiency of the explosion decreases for any degree of expansion of the explosion products, and the thermal losses increase.

\section{Methods}

While theoretical calculations of explosive energy losses during expansion of gaseous explosion products and also energy losses in rocks, associated with the origination of shock waves in rocks thermodynamic method research into proceeded processes have been used.

\section{Results and discussion}

Taking into account (2), the expression for estimating the dissipative energy losses of the explosion $Q_{\text {loss }}$ can be written as:

$$
Q_{\text {loss }}=Q\left(\frac{P_{0}}{P_{i}}\right)^{\frac{k-1}{k}}
$$

For condensed explosives, the estimates of dissipative losses following formula (3) are in the qualitative nature, not quantitative. However, such an assessment reveals important dependences of dissipative losses on the properties of explosives. 
If the pressure of explosion products $P_{i}$ arising from the detonation of an explosive, taking into account their molecules intrinsic volume, is determined by the formula:

$$
P_{i}=\frac{P_{0} V_{0} T_{1}}{273 V\left(1-\frac{\alpha}{V}\right)},
$$

where $V_{0}$ - the volume of detonation products at $0{ }^{\circ} \mathrm{C}$ and pressure $P_{0}=0.1 \mathrm{MPa} ; V_{-}$ the volume of the charging cavity; $T_{1}$ - the explosion temperature, $\mathrm{K} ; \alpha$ - the intrinsic volume of molecules (covolume) of explosion products [7].

When the explosive loading density is $\rho_{E X}=500-1000 \mathrm{~kg} / \mathrm{m}^{3}$, the covolume of explosion products $\alpha=0.001 \mathrm{~V}$. When the explosive density is more than $1000 \mathrm{~kg} / \mathrm{m}^{3}$ $\alpha=0.0006 \mathrm{~V}$. If the volume $V$ of the charging cavity contains a unit mass of explosive $(1 \mathrm{~kg})$, then $1 / V=\rho_{E X}$ is the loading density.

Then formula (4) can be written:

$$
P_{i}=\frac{P_{0} V_{0} T_{1} \rho_{E X}}{273\left(1-\alpha \rho_{E X}\right)} .
$$

After substituting (5) into (3), we obtain the formula for calculating the dissipative losses $Q_{\text {loss }}$ during the blast of the explosive charge:

$$
Q_{\text {loss }}=Q\left(\frac{273\left(1-\alpha \rho_{E X}\right)}{V_{0} T_{1} \rho_{E X}}\right)^{\frac{k-1}{k}} .
$$

The share of dissipative losses from the energy stored in an explosive substance $\xi=Q_{\text {loss }} / Q$ is

$$
\xi=\frac{273\left(1-\alpha \rho_{E X}\right)}{V_{0} T_{1} \rho_{E X}} .
$$

The estimation of dissipative energy losses of explosives with different properties is given in Table 1.

Table 1. Parameters of explosives and the share of thermodynamic losses during their detonation.

\begin{tabular}{|l|c|c|c|c|c|c|}
\hline Explosive & $\begin{array}{c}\text { Density, } \\
\rho_{E X}, \mathrm{~kg} / \mathrm{m}^{3}\end{array}$ & $\begin{array}{c}\text { Volume } \\
\text { explosion } \\
\text { gases, } V_{0}, \\
\mathrm{~m}^{3} / \mathrm{kg}\end{array}$ & $\begin{array}{c}\text { Heat of } \\
\text { explosion, } \\
Q, \mathrm{~kJ} / \mathrm{kg}\end{array}$ & $\begin{array}{c}\text { Blast } \\
\text { temperature, } \\
T, \mathrm{~K}\end{array}$ & $\begin{array}{c}\text { Indicator } \\
\text { adiabats, } \\
k\end{array}$ & $\begin{array}{c}\text { Share } \\
\text { dissipative } \\
\text { losses, } \%\end{array}$ \\
\hline $\begin{array}{l}\text { Ammonite } \\
\# 6 \mathrm{GV}\end{array}$ & 900 & 0.86 & 3930 & 2873 & 1.24 & 11.0 \\
\hline $\begin{array}{l}\text { Ammonium } \\
\text { nitrate }\end{array}$ & 900 & 0.98 & 1425 & 1350 & 1.30 & 9.0 \\
\hline $\begin{array}{l}\text { PETN } \\
\text { explosive }\end{array}$ & 1100 & 0.78 & 5908 & 4010 & 1.22 & 16.0 \\
\hline Anemix & 1200 & 1.01 & 2960 & 2160 & 1.20 & 17.5 \\
\hline
\end{tabular}

Thus, dissipative losses during the blast of an explosive charge depend not only on the heat capacities of the explosion products, which affect the adiabatic index, but also on other 
explosive properties. With a decrease in the adiabatic index, dissipative heat losses increase. Dissipative losses also depend on the density of the explosive, the temperature of the explosion and the volume of the gaseous products.

Energy losses during a blast can be associated with the origination of shock waves in rocks, which leads to a significant decrease in the efficiency of the explosion. The parameters of the shock wave depend on the rocks structural properties, which determine the mechanism of their destruction during an explosion.

Especially significant dissipative losses can be in incoherent porous and fragile easily crushed rocks.

For rocks, two mechanisms of destruction in the shock wave front can be considered: when the rock is porous, with a sufficiently high concentration of pores (the first case), and when the rock consists of mineral grains that do not differ much in strength (second case).

In the first case, when a shock wave passes through a porous rock, each pore serves as a stress concentrator, and the destruction of the rock begins at the locations of the pores. The rock has time to destroy in the zone of the shock wave; otherwise, the shock wave will not propagate.

In the second case, the rock can be considered as a continuous homogeneous medium. Non-porous polymineral rock, which consists of defect-free (microcracks) mineral grains, whose properties are significantly different, in the front of a weak shock wave is destroyed in less durable grains. If the size of strong grains is more than the width of the front of the shock wave, then they will destroy under the action of shear stresses arising when they are flowed around by the shock wave. When the rock consists of large grains of minerals with different properties, a shock wave arises in each grain, but the velocities of the shock waves and the mass velocities of the rock in different grains will also be different. This leads to the destruction of the grain into small particles.

The energy loss associated with the occurrence of $W_{\text {loss }}$ shock waves can be estimated as follows:

$$
W_{\text {loss }}=\int_{V_{i}}^{V_{s h}} P(V) d V
$$

where $P(V)=\frac{P_{i} V_{i}^{k_{0}}}{V^{k(V)}} ; P_{i}$ and $V_{i}-$ initial pressure and volume of explosion products; $k_{0}$ and $k(V)$ - are, respectively, the initial adiabatic index for the volume $V_{i}$ and the adiabatic index for the volume $V ; V_{s h}$ - the volume of rock, which is affected by the shock wave.

Therefore

$$
W_{\text {loss }}=P_{i} V_{i}^{k_{0}} \int_{V_{i}}^{V_{s h}} \frac{d V}{V^{k(V)}} .
$$

When expanding the explosion products, the adiabatic index decreases from $k_{1}=3$ to $k_{2}=1.33$. Since it is not possible to take into account the dependence of the adiabatic index on the explosion products volume, it is usually assumed that $k$ is constant. If the arithmetic mean value of the adiabatic index $\bar{k}=2.16$ is used in calculations of the energy losses of the explosion in the shock wave, then equation (8) can be integrated:

$$
W_{\text {loss }}=\frac{P_{0} V_{i}^{k_{0}+k+1}}{\bar{k}-1}-\left(1-\left(\frac{V_{i}}{V_{s h}}\right)^{\bar{k}-1}\right),
$$

Let us determine the energy losses of the explosion in the shock wave of the Ammonite $\# 6 \mathrm{GV}$ borehole with a diameter of $d=250 \mathrm{~mm}$ and a length of $1 \mathrm{~m}$. The volume occupied 
by this amount of explosives is $V_{i} \sim 0.05 \mathrm{~m}^{3}$. Calculated by the formula (5), the initial pressure on the borehole of the well in the explosion of Ammonite \#6GV is $P_{i}=8.14 \mathrm{GPa}$. Substituting the values of $P_{i}$ and $V_{0}$ into formula (9), we obtain the expression for estimating the energy loss of an explosion in a shock wave:

$$
W_{\text {loss }}=283 \cdot 10^{7}\left(1-\left(\frac{V_{i}}{V_{s h}}\right)^{1.16}\right) .
$$

Table 2. The calculation of the energy loss of the explosion in the shock wave for different ratios of $V_{i}$ and $V_{s h}$, when the ratio of $V_{i} / V_{s h}<1$.

\begin{tabular}{|c|c|c|c|c|}
\hline$V_{i} / V_{\text {sh }}$ & 0.95 & 0.91 & 0.83 & 0.66 \\
\hline$\left(V_{i} / V_{\text {sh }}\right)^{1.16}$ & 0.94 & 0.98 & 0.80 & 0.62 \\
\hline $1-\left(V_{i} / V_{\text {sh }}\right)$ & 0.116 & 0.11 & 0.20 & 0.38 \\
\hline$W_{\text {loss }}, \mathrm{MJ} / \mathrm{m}^{3}$ & $1.7 \cdot 10^{6}$ & $3.1 \cdot 10^{6}$ & $5.7 \cdot 10^{6}$ & $10.8 \cdot 10^{6}$ \\
\hline
\end{tabular}

The table shows that the greater the volume of rock, which is affected by the shock wave, the greater the energy loss of the explosion.

\section{Conclusions}

1. The share of the explosive energy dissipated in the near zone of the explosion depends on the properties of the explosives that determine the shock wave parameters which originate during detonation and properties of the destroyed rock. Especially significant dissipative losses can be in incoherent porous and fragile easily crushed rocks.

2. A theoretical estimate of the dissipative energy losses of the explosion during the rocks destruction showed that the dissipation depends on the average heat of explosion products capacity, which determines the numerical values of the explosives adiabatic index. With a decrease in the numerical value of the adiabatic index, the efficiency of the explosion decreases and, accordingly, the dissipative heat losses increase. It is established that dissipative energy losses of the explosion also depend on the explosive density, the explosion temperature and the gaseous detonation products volume.

3. Significant energy losses of explosives during the destruction of rocks are associated with propagation of the shock waves generated by the explosion. Calculations of the explosion energy losses in the shock wave show that the greater the rock volume, which is affected by the shock wave the greater the dissipative losses of explosion energy.

\section{References}

1. Kryukov, G.M. (2009). Evaluation of the time of rocks destruction by blasting the long charges of industrial explosives, Gornyy informatsionno-analiticheskiy byulleten, 1, 8152

2. Kachanov, A.N. (2011). About role of wave and gas factors in process blasting predestruction and disintegration of rocks, Vzryvnoye delo. 105 (62), 16-23

3. P.K. Sign, Brownkohle - Surface Mining 52, 4 (2000)

4. Kurinnoy, V.P. (2018). Teoreticheskiye osnovy vzryvnogo razrusheniya gornykh porod. Dnepr: ChMP Economika

5. Efremov, E.I. (2010). Method of operation by crushing zone sizes of solid mediums, Suchasni resursoenergozberigaiuchi tekhnologii girnychogo vyrobnytstva, 8, 7-10

6. Dubnov, A.V., Bakharevich, N.S., Romanov, A.M. (1985). Promyshlennyye vzryvchatyye veshchestva. Moskva: Nedra 
7. Kutuzov, B.N. (1981). Laboratornyye i practicheskiye raboty po razrusheniiu gornykh porod. Moskva: Nedra 